\title{
Estratégias antropológicas incipientes para uma etnografia digital: uma discussão a partir de narrativas midiáticas sobre violências sexuais, de gênero e trotes em uma Faculdade de Medicina
}

\author{
FELIPE PAES PIVA \\ Universidade de São Paulo, São Paulo, São Paulo, Brasil \\ felipe.piva@usp.br
}

DOI 10.11606/issn.2316-9133.v29i2pe175324

resumo Este artigo tem como base a pesquisa desenvolvida entre 2017 e $2018 \mathrm{com}$ o propósito de entender como os atuais processos de disputa política em torno da significação de categorias de violências sexuais, de gênero e trotes têm sido apropriados e representados pela mídia hegemônica brasileira. Para isso, foi analisada a construção da narrativa midiática desses casos nas faculdades paulistas, principalmente na Faculdade de Medicina, que foram alvo de uma Comissão Parlamentar de Inquérito na Assembleia Legislativa do Estado de São Paulo, em 2014. A repercussão midiática desses casos promoveu a nomeação pública de certas práticas como estupro, abuso e violência sexuais, práticas que, pouco tempo antes não eram necessariamente significadas desta forma. Buscou-se discutir não apenas os resultados obtidos, mas também estratégias possíveis para utilização do digital como campo de pesquisa antropológica e a construção de um arquivo digital como base de dados.

palavras-chave Mídia. Violência de gênero. Trotes. Antropologia digital.

Incipient anthropological strategies for a digital ethnography: a discussion based on media narratives about sexual and gender-based violence and hazing at a Faculty of Medicine

abstract The article is based on a research developed between 2017 and 2018 seeking to understand how the current political dispute of meaning to the categories of sexual and gender violence, and hazing have been appropriate and represented by the Brazilian hegemonic media. It analyzes the construction of media narrative on gender and sexual violence in São Paulo colleges, mainly at the Faculty of Medicine. In 2014, this Faculty was party in a Parliamentary Commission of Inquiry, at the Assembleia Legislativa de São 
Paulo. The media repercussion of these cases promoted the public naming of certain practices such as rape, sexual abuse and violence, that until recently were not necessarily meant in this way. It discusses also the possible strategies for using digital as an anthropological research field and the construction of a digital archive as a database.

keywords Media. Gender violence. Hazing. Digital anthropology.

\section{Estrategias antropológicas incipientes para la etnografía digital: las} narraciones de los medios de comunicación sobre la violencia sexual, el género y las novatadas en una Facultad de Medicina

resumen El artículo se basa en la investigación desarrollada entre 2017 y 2018 con el propósito de comprender cómo los actuales procesos de disputa política en torno al significado de las categorías de violencia sexual, género y novatadas han sido apropiados y representados por los medios de comunicación hegemónicos brasileños. Para ello, se analizó la construcción de la narración mediática de estos casos en las facultades del estado de São Paulo, Brasil, especialmente en la Facultad de Medicina. La Facultad fue objeto de una Comisión Parlamentaria de Investigación en la Assembleia Legislativa do Estado de São Paulo en 2014. La repercusión mediática de estos casos promovió la designación pública de ciertas prácticas como la violación, el abuso sexual y la violencia, prácticas que, poco antes, no necesariamente se entendían de esta manera. Se trató de discutir no sólo los resultados obtenidos, sino también las posibles estrategias para utilizar lo digital como campo de investigación antropológica y la construcción de un archivo digital como base de datos.

palabras clave Media. Violencia de género. Novatadas. Antropología Digital.

\section{Introdução}

Ao longo da minha graduação em Ciências Sociais tive pouco contato em sala de aula com uma bibliografia que tratasse do empreendimento etnográfico no meio digital. Ao desenvolver um projeto de Iniciação Científica ${ }^{1}$, entre 2017 e 2018, sobre os casos de violências sexual, de gênero e trote, tendo como ponto de partida os portais digitais de portais brasileiros, as minhas primeiras tentativas de conceber como seria minha entrada no campo digital foram marcadas por muitos questionamentos e frustrações pela falta de outros referenciais metodológicos.

Alguns pressupostos mais tradicionais do fazer etnográfico a que eu havia sido apresentado até então, de certa forma, chocavam diretamente com meu objeto e contexto. Diversos questionamentos persistiram: como eu poderia estabelecer uma entrada no campo quando ele não me requisita, necessariamente, deslocar de um local para outro? Onde terminaria e começaria o meu trabalho de campo? Como eu poderia separar o "estar lá" e o

\footnotetext{
${ }^{1}$ Esta pesquisa contou com financiamento do PIBIC $(\mathrm{CNPq})$ e foi orientada pela Dra. Carolina Parreiras.
} 
"estar aqui"? Por fim, quais estratégias eu poderia empregar em uma atitude etnográfica, ou melhor, como eu poderia estabelecer estratégias para transitar da figura de "internauta" para a de etnógrafo sem que houvesse uma delimitação rígida das fronteiras que distinguem esses âmbitos? Parte desses questionamentos puderam ser respondidos pelas leituras antropológicas feitas nas aulas, outra parte requisitou entrar em contato com os desenvolvimentos etnográficos da e $n a$ internet. Ambas me ajudaram a reavaliar minhas incertezas, e completa inexperiência, por meio de uma reflexão mais ampla e crítica do fazer etnográfico. As bases fundamentais dessa empreitada intelectual e alguns de meus questionamentos e confrontos são desenvolvidos a seguir.

Peirano (2014) advoga que a pesquisa de campo não tem momento certo para começar nem para acabar. A pesquisa de campo decorre de momentos arbitrários que dependem da potencialidade de estranhamento, de uma necessidade de examinar por que certos eventos, vividos ou observados, nos surpreendem e instigam. A compreensão dessas relações nos torna não somente investigadores, mas agentes na etnografia. Segundo a autora, a etnografia é primordial para a antropologia, pois a empiria caracteriza seu empreendimento, não haveria antropologia sem empiria. Dessa forma, a empiria é tudo aquilo que nos afeta os sentidos, os materiais coletados e os questionamentos que se apresentam.

Outro ponto muito importante apresentado pela autora é a dissolução da oposição entre empiria e teoria, já que a teoria é aprimorada pelo constante confronto com novos dados empíricos. Consequentemente, há a constante necessidade de se conceber novas estratégias e formas de pesquisa, pois é a partir de uma permanente recombinação intelectual que se desenrola o refinamento da antropologia. A constante emergência de novas pesquisas deve nos levar a uma constante recomposição da antropologia.

Quanto aos questionamentos envolvendo o sentido mais tradicional da observação participante, me apeguei a clássica definição de Roberto Cardoso Oliveira (1998), para o qual a observação participante levaria o pesquisador a assumir um papel digerível para seus interlocutores para que assim se possa viabilizar as interações, visando sempre o estabelecimento de uma relação dialógica, nas quais os diferentes horizontes semânticos entrem em confronto no "encontro etnográfico". Todavia, o que me proponho a lidar são textos midiáticos, o acesso aos interlocutores esperados apenas se dá por intermédio da narrativa que esses textos apresentam. Portanto, o que fazer quando o ouvir, como um ato cognitivo da antropologia, permanece numa relação unidimensional e sem que haja um diálogo direto que possibilite este confronto? Dar atenção para as diferentes formas de pesquisa que se desenvolveram sobre o assunto até então me pareceu ser um caminho viável.

Nesse sentido, foi necessário se atentar para as diversas formas que os processos midiáticos se dão através da tecnologia e o que isso implica no estudo etnográfico, pois, como aponta Parreiras (2015), o meio tecnológico/digital é fundamental para o entendimento da vida social contemporânea. Ele é um campo marcado por inesperadas e constantes mutações que demandam do pesquisador uma adaptação contínua a novos referenciais teóricos. 
As realidades locais e globais são mediadas por diferentes veículos e plataformas midiáticos. Contudo, isso não implica uma relação de continuidade ou similaridade entre uma identidade em contexto off-line e online. As relações e as representações intersubjetivas são produzidas em ambas pelas interações e práticas que vão sendo estabelecidas. Nesse contexto, o estudo dessas interações e práticas ajudam no entendimento de que "mundos digitais" são simplesmente outras arenas que, juntamente com os "mundos não digitais", expressam os mesmos conjuntos, não havendo assim razões para privilegiar um em detrimento de outro. Uma perspectiva antropológica sobre essas mediações deve se preocupar em entender os motivos de algumas mídias serem percebidas como mais mediadas do que outras. Por conseguinte, ao invés de ver os mundos pré-digitais como menos mediados, precisamos estudar como que o desenvolvimento das tecnologias digitais criou essa ilusão (HORST; MILLER 2012).

A partir desses pressupostos, empreguei a estratégia metodológica de Hine (2000): tomar a internet como texto produzido em contextos culturais específicos, que podem ser acessíveis ao pesquisador mesmo após um longo tempo de sua produção. Fiz junção disso com a estratégia textual de Geertz (2015), na qual a cultura de um determinado segmento social pode ser entendida como conjunto de textos, nos quais o antropólogo busca compreensão das interpretações que colocados pelos interlocutores.

Entender esse conjunto de textos exigiu estratégias específicas, por isso, procurei aplicar métodos de trabalhos de campo em arquivos. Postulei que, entre arquivos físicos e virtuais, lida-se basicamente com textos, sendo que esses representam um sistema de enunciados, verdades parciais, interpretações históricas e culturalmente constituídas, que estão permanentemente sujeitas a novas leitura e interpretações (CUNHA 2014).

Segundo Lowenkron e Ferreira (2014), documentos etnográficos requerem que o pesquisador estabeleça um "diálogo com" e considere a agência daqueles que não são imediatamente identificados como sujeitos de pesquisa: as pessoas sendo documentadas e o próprio registro textual. É também compreender as micropolíticas que, no caso específico desta pesquisa, ocorriam o conjunto de atores sociais mobilizados nas notícias. Portanto, é não perder de vista a natureza assimétrica dessas relações que, representadas nos relatos jornalísticos e nas pesquisas, enquanto campos de pesquisa, definem um espaço produtivo de diferentes reflexões e potencialidades do conceito de agência, num sentido antropológico, como a capacidade social e culturalmente mediada de ação.

Por fim, procurei desenvolver minhas análises me valendo do comentário como gênero literário antropológico. Como postula Fabian (2008), tal prática não é uma mera colagem, mas uma justaposição de elementos. Para qualificar como gênero literário, o comentário deve ser mais que uma breve exposição de excertos, mas, como forma etnográfica, requer a copresença substancial do texto, com bases interpretativa, analítica e historicamente baseadas em seu conteúdo. Sendo assim, metaforicamente, tal empreendimento consiste em comentários feitos de outros comentários, e esses se relacionam aos primeiros como tijolos na fortificação de uma casa. Uma construção de 
comentários sobre comentários que se autossustenta para fins analíticos. Embora a construção narrativa construída aqui prossiga uma ordem cronológica, é importante frisar que tal construção é uma ficção antropológica, pois os eventos aqui apresentados são relacionados segundo a narrativa criada, não são encontrados na mesma ordenação e relação nas fontes midiáticas. Desse modo, o texto desenvolvido tem um caráter experimental, isto é, diferentes posições são experimentadas, sem pretensão a uma conclusão ou a um conhecimento acumulativo sobre os assuntos em discussão. Tal narrativa opera através de várias relações e oposições e contrastes que funcionam estritamente no interior dos limites da trama antropológica (STRATHERN 2006).

\section{Construindo um pequeno arquivo digital: algumas possibilidades analíticas}

Quanto aos desenvolvimentos metodológicos práticos, o levantamento de fontes se deu pela estratégia de acompanhar o fluxo referencial das notícias, partindo daquelas que marcam o início da publicização. Os portais selecionados empregam artifícios referenciais dentro e fora do corpo da notícia e isso estabelece relações entre seus conteúdos. A partir disso, fui seguindo os fluxos estabelecidos para realizar a reconstrução da narrativa midiática. Não procurei dar conta de todas as notícias que pudessem ter sido veiculadas neste período, pois pareceu mais produtivo focar em quatro veículos: Estadão, Folha de S. Paulo, G1 e HuffPost Brasil. Essa escolha se deu por um levantamento prévio que demonstrou que tais portais tiveram as maiores e mais diversas perspectivas na representação dos casos, o que garantiu a delimitação de um horizonte possível de análise. O registro das notícias passou por diferentes etapas de seleção. Construí uma tabela qualitativa que adquiriu a função de um quadro sinóptico por agregar tanto o registro de informações mais gerais das notícias, quanto um mais detalhado, resultante da análise conjunta dos dados.

Fiz a captura do conteúdo da notícia com ajuda do aplicativo Evernote. Com ele, consigo capturar o corpo textual da notícia sem perder nenhuma parte do conteúdo, removendo quaisquer recursos presentes na interface do portal (anúncios, menus, barra de pesquisa) que não são relevantes. A utilização do programa apresentou uma facilidade de captura e armazenamento das notícias, permitindo o desenvolvimento de um banco de dados acessível em diversas plataformas. A estratégia inicial envolvia a impressão das notícias, o que não permitia remover os outros recursos. Com isso, o registro textual ficava visualmente carregado, dificultando a leitura. Também era inviável manter tantos registros em papel de forma sistemática, o que me fez procurar outras alternativas para agrupar as notícias. Por fim, o aplicativo permitiu mais possibilidades de organização e classificação dos dados, devido aos recursos que oferece. Com isso, há também uma maior maleabilidade do conteúdo textual, algo que o registro impresso não possibilita.

Após esse momento, fiz a inserção de cada notícia no quadro sinóptico pelo preenchimento de informações identificatórias: data de publicação, portal em que foi publicado, título da notícia, breve resumo da notícia. Fui repetindo isso até conseguir dar 
conta de um número substancial de notícias relacionadas ao tema. Para isso, restringi o recorte temporal feito previamente. Para tanto considerei o momento inicial das denúncias e sua publicização, em novembro de 2014, passando pela finalização da CPI em março de 2015, e, por fim, pelos desenvolvimentos posteriores que se estendem até 2018. Com esses pressupostos, foi feito o registro de mais de 500 notícias, centrando predominantemente nos quatro portais descritos. Contudo, os desenvolvimentos posteriores à CPI não tiveram grande presença nestes quatro portais, portanto ampliei as fontes para portais que até então não tinham sido trabalhados.

Com o quadro já preenchido, organizei os registros por ordem cronológica. Isso me permitiu verificar quais tópicos se repetiam mais nesses portais. Delineei uma estrutura temporal desses eventos, listando em cada evento as notícias que faziam parte de sua circunscrição, registrando a data da publicação, o portal e o título da matéria. Fiz isso para todo o período descrito. Com esses desenvolvimentos, tive uma primeira sistematização dos dados, pois, para a maioria dos eventos, foi possível verificar que, no mínimo, três dos quatro veículos haviam publicado sobre, ou seja, para um determinado evento havia desenvolvimentos diversos, ênfases diferenciadas segundo o editorial de cada portal.

Por fim, foram analisadas as notícias agrupadas por seu respectivo evento. Cada notícia foi lida com atenção, procurando sintetizar as nomeações de violência presentes no texto e os outros eventos que são citados. Por último, registrei as falas mais marcantes e quem as disse. Esse detalhe acabou sendo também sistematizado para além de cada evento. Todos os atores sociais e instituições enunciados e referidos nas notícias foram inseridos numa listagem segundo sua instância de poder nos casos - ou seja, se fazem parte de órgãos internos das faculdades paulistas ou externos, suas divisões internas - comissões, coletivos, grupos, atuação. Tal esquema possibilitou um melhor entendimento da potencialidade da mobilização dos atores sociais e das instituições nas narrativas midiáticas dos casos de agressão sexual nas faculdades paulistas. Também possibilitou mapear os momentos em que certas vozes são privilegiadas e outras silenciadas. Feita a análise de um evento, voltei-me para uma inserção mais detalhada no quadro sinóptico utilizando-me dos dados colhidos. Em suma, foi esse o caminho percorrido para rastrear quais foram os pontos mais discutidos do processo e também as diferentes formas que cada portal retratou o mesmo assunto para, por fim, realizar uma análise sistemática e comparativa.

\section{Conceituando e contextualizando os discursos midiáticos no meio digital}

Curran, Fenton e Freedman (2012) afirmam que, ao longo dos anos 1990, políticos, economistas, ativistas, acadêmicos e jornalistas de todas partes do mundo predisseram que a internet iria mudar o mundo. Não só tal tecnologia iria revolucionar a organização da economia mundial levando a um surto de prosperidade, como também inauguraria uma nova era global de democracia cultural na qual usuários, como soberanos, ordenariam as coisas no mundo. De modo geral, enquanto um meio de comunicação global, a internet iria 
encolher o mundo, abrir novas pontes entre culturas promovendo diálogos transformadores entre nações e, assim, nutrindo um melhor entendimento da diversidade global. Com isso, a internet seria responsável por um rejuvenescimento da democracia através de referendos populares e governos digitais propiciando uma democracia direta, em seu sentido mais utópico de paridade política. Consequentemente, os fracos e marginalizados de todo globo iriam se empoderar, liderando a queda dos autocratas e reordenando as relações de poder. Nem a velha mídia poderia permanecer a mesma, a internet estava democratizando o jornalismo, o poder midiático estaria se deslocando da velha elite midiática industrial para os blogs, dando assim fim a era do controle dos grandes conglomerados midiáticos com o fim de seu monopólio comunicativo, ela tenderia a decompor e morrer muito em breve. Em suma, a internet foi tida, naquele momento, como uma força transformadora e avassaladora que não poderia ser parada, iria mudar o mundo para além do reconhecível. Ao menos, era o que todos esperavam.

As pessoas, em seus primeiros contatos com uma nova tecnologia de comunicação interpessoal, tendem, segundo Baym (2010), a reagir geralmente de dois modos: ou expressam ansiedades e preocupações quanto a uma crescentemente superficialidade social, tida como inerente das novas tecnologias, ameaçando a integridade e a autenticidade dos relacionamentos interpessoais, ou encaram as novas tecnologias como promessas de maiores e melhores oportunidades de conexões interpessoais, como uma rota para novas oportunidades e relacionamentos. Ambas tendências têm longas histórias culturais, a primeira é denominada de determinismo tecnológico, a segunda, de construção social da tecnologia. Elas refletem um senso geral de que as mídias digitais estão mudando a natureza quantitativa e qualitativa das nossas conexões sociais.

É através da comunicação que as pessoas designam significados simbólicos às tecnologias. Enquanto indivíduos e grupos se comunicarem pelas mídias digitais, como argumenta Coleman (2010), haverá circulações, reimaginações, exclusões, traduções, revisões e remarcações de um amplo conjunto de representações, experiências e identidades culturais. Porém, os modos precisos que essas dinâmicas se desdobram não podem ser totalmente antecipados, são sempre formulações contingentes e dinâmicas. Desse modo, para entendermos as "novas mídias" precisamos considerar tanto suas características tecnológicas como também as presunções, os valores pessoais, culturais e históricos que essas características evocam.

De modo geral, podemos afirmar que o crescimento da internet não tem minado as grandes organizações midiáticas. Pelo contrário, permitiu que elas estendessem sua hegemonia utilizando as diversas tecnologias emergentes (CURRAN; FENTON; FREEDMAN 2012). As grandes organizações midiáticas, por exemplo, rapidamente "colonizaram" o segmento de notícias da internet. Ramos (2012) afirma que os grandes conglomerados jornalísticos foram as primeiras grandes empresas a se instalarem de forma continuada nas mídias digitais. Hoje, praticamente todos os grandes jornais e revistas possuem também blogs ou, ao menos, colunas eletrônicas e perfis nas mídias sociais que se 
aproximam bastante do formato blog, de periodicidade diária ou semanal e que possuem uma seção de comentários. Consequentemente, a grande maioria dos blogueiros mais conhecidos e lidos são também colunistas em jornais impressos, pois a visibilidade e o prestígio do jornal se transferem, em parte, para a figura do "blogueiro". Atualmente, de um modo geral, os blogs são, para os jornalistas, quase que uma extensão de seu trabalho offline.

As práticas e as redes de produção das estruturas midiáticas constroem suas mensagens segundo referenciais estabelecidos em sua própria estrutura. Para que se possa entender como a pluralidade dessas narrativas reverberaram nas diversas esferas, o modelo de codificação/decodificação, proposto por Stuart Hall (2006) pode ser útil. Para ele, as estruturas midiáticas são um complexo de produções diversificadas e plurais. Para que esses discursos venham a se tornar significativos é necessário que sejam codificados de acordo com referenciais hegemônicos. Na estrutura destes referenciais há uma hierarquia de "sentidos preferenciais", em segmentos de legitimações, restrições e sanções de ordem performativas. Entretanto, como reforça o autor, os sentidos dominantes não se estabelecem em processos de mão única. A decodificação se dá em códigos negociados, nos quais as significações hegemônicas se misturam com significações situacionais e localizadas. Portanto, nem toda assimilação do hegemônico é signo de submissão, tampouco a recusa é resistência.

O poder midiático é comumente analisado como uma designação de como outras forças poderosas - econômicas, políticas, culturais e sociais - se utilizam dos mecanismos midiáticos para seus próprios interesses. Contudo, para Couldry e Curran (2003), essas análises sobre o poder midiático esquecem o que deveria ser seu ponto de partida: o poder midiático não deve se restringir a apenas analisar a competição entre diferentes forças externas a ele, cujo conflito é retratado por meio da cobertura midiática. Tal conflito que, inicialmente, pode parecer ser sobre outras formas de poder, na verdade, acaba sendo sobre o controle dos recursos representacionais da sociedade. O poder simbólico, segundo Bourdieu (1989), se refere ao poder de construção da realidade social, dessa forma, o sentido primário do poder midiático é, portanto, a concentração de poder simbólico. Sua efetividade depende, parcialmente, em ser esquecido, quando tomamos como certo que é estritamente nas instituições midiáticas oficiais, e em nenhum outro lugar, que devemos procurar os fatos sociais e a maioria de nossas ficções confiáveis.

Ao invés de conceituar as estruturas midiáticas como sendo permanentes ou imanentes, Couldry (2003) as considera como processos sociais, tornando-se assim abertas para disputas por outros tipos de processos sociais da prática midiática. Nas últimas décadas, as mídias convencionais tornaram-se ainda mais pervasivas e visíveis globalmente, sendo, em grande parte, conduzidas por necessidades e pressões exercidas por uma crescente expansão da economia capitalista. De modo geral, o principal objetivo dessas mídias tem sido o de agregar e mobilizar suas audiências para os anunciantes que as financiam e as tornam rentáveis. Se por um lado, as contínuas pressões comerciais são certamente hegemônicas, por outro, elas não são monolíticas, não seguem sem oposições e disputas. 
Dado que as violências de gênero e sexuais que são abordadas neste artigo foram trazidas ao conhecimento público por meio das narrativas midiáticas, isso implica uma série de especificidades próprias da construção deste discurso. Se certos incidentes dão motivo para uma intensa cobertura jornalística, é também porque eles estavam em ressonância com inúmeros problemas da sociedade, midiaticamente constituídos (CHAMPAGNE 1998). Tal ressonância pode ser observada nas mudanças das representações midiáticas quanto à violência sexual, por exemplo. Landini (2006) observa que é, na década de 1990, que se iniciou uma mudança de representação devido a uma nova sensibilidade social, na qual os crimes de estupros, antes alvo de exíguas reportagens, passaram a ser escândalos jornalísticos. Essa mudança é bastante significativa na forma de retratar a violência sexual, que passa a ser "analisada", entendida como algo que requer mais do que uma simples expressão de horror e recusa. Além disso, há uma maior profundidade na análise dos casos, pois esses passam a ser acompanhados por um tempo maior, coisa que antes se restringia a episódios fragmentados e únicos. Sendo assim, o jornalista não se limitava mais a simplesmente "dar a notícia", mas procurava analisar e entrevistar especialistas que pudessem contribuir. Nesse sentido, também começaram a empregar a linguagem científica e dados quantitativos na representação dos casos.

\section{O Marco Inicial}

No dia 11 novembro de 2014, a ALESP publicou uma nota, em seu site oficial, relatando que três vítimas de violência sexual haviam prestado depoimento, no qual narraram as agressões sofridas em festas organizadas pela Associação Atlética Acadêmica (AAA) da Faculdade de Medicina da Universidade de São Paulo (FMUSP). Também alegavam a pressão a que foram submetidas para não "manchar a imagem da instituição [FMUSP]"2. Em questão de horas, as denúncias eram escrutinadas em diversos veículos da mídia hegemônica brasileira: "Alunas denunciam estupros em festas da Medicina da USP"3, "Violência sexual, castigos físicos e preconceito na Faculdade de Medicina da USP" " "Vítimas de estupro em festas da USP denunciam abusos à ALESP" "Alunas denunciam estupros em festas da Faculdade de Medicina da USP"6, "Promotora diz que oito estupros ocorreram na Faculdade de Medicina da USP; instituição anuncia centro de direitos humanos"7, "Em audiência pública, alunas relatam casos de abuso sexual em festas de estudantes de medicina da USP"8 "Inquérito do MPE cita oito casos de estupro na Faculdade de Medicina da USP"9.

\footnotetext{
$2 \operatorname{ALESP}(11 / 11 / 14)$

${ }^{3}$ Estadão $(11 / 11 / 14)$

${ }^{4}$ Ponte $(11 / 11 / 14)$

${ }^{5} \mathrm{G} 1(12 / 11 / 14)$

${ }^{6}$ Folha de S. Paulo $(12 / 11 / 14)$

${ }^{7}$ Huffpost Brasil (12/11/14)

${ }^{8}$ R7 (11/11/14)

${ }^{9}$ Veja $(12 / 11 / 14)$
} 
Este foi o marco inicial da publicização do que viria a se tornar a CPI das Violações dos Direitos Humanos nas Faculdades Paulistas, processo no qual os deputados paulistas realizaram uma "devassa" contra formas de desrespeito aos direitos humanos em universidades públicas e privadas de $\mathrm{SP}^{10}$.

Um dia após a audiência pública, diretores da FMUSP se reuniram para discutir as denúncias de violência sexual contra mulheres e abusos contra estudantes negros e negras e homossexuais dentro da faculdade. Segundo a ouvidoria da instituição, não havia queixa sobre nenhum dos dois casos de estupro, "a ouvidoria não foi procurada nos casos que, agora, vieram à luz por meio da imprensa e, embora soubéssemos de sua existência, não pudemos agir", "fomos procurados, entretanto, por dois estudantes que denunciaram estar sendo vítimas de acusação falsa e pública de violência sexual, que não teriam cometido." ${ }^{11}$ Anunciou-se também a criação de um centro de direitos humanos para dar assistência jurídica e psicológica para apoiar alunos da FMUSP que se sentirem "vítimas de qualquer tipo de violação", como agressões sexuais, machismo, racismo e homofobia. Na nota oficial, divulgada pela faculdade, afirmou-se que o centro receberia denúncias identificadas ou anônimas, tendo como primeiro objetivo "garantir todo o apoio à vítima caso haja alguma violação" e, depois, punir os responsáveis ${ }^{12}$.

Os efeitos começaram no mesmo dia, com o pedido de afastamento de Paulo Saldiva, renomado professor titular da FMUSP e presidente da Comissão de Direitos Humanos da unidade. Formada por professores, alunos e funcionários, de junho a outubro de 2014, a Comissão apurou os casos de abusos praticados dentro da instituição. Saldiva teria tomado a decisão após presenciar os depoimentos na ALESP. Para ele, "foi a gota d'água". Teria ficado surpreso, pois os fatos narrados eram absolutamente desconhecidos. "Eu conhecia um lado (da FMUSP) que era muito mais prazeroso. Alunos brilhantes, atividade de cursinho para gente carente, atividades especiais na periferia com vários alunos”. Seu sentimento, como professor, era de que ele teria sido incapaz de detectar os ocorridos. Afirmou que a falta de uma ação construtiva e proativa do corpo discente fez com que os alunos fossem submetidos a situações inaceitáveis.

O evento descrito acima se apresentou de forma complementar nas matérias do $\mathrm{G} 1^{13}$ e do Estadão ${ }^{14}$. Todavia, a Folha ${ }^{15}$ apresenta uma perspectiva contrastiva dos posicionamentos de Saldiva. Nela, ele afirmava que "a faculdade nunca fez nada" e também "se comportou mal. Houve demora da congregação, ficaram na defensiva. Há uma crise de conduta, de valores. Cansei de engolir sapo", "chega de intenção. É preciso prática”. Além disso, alerta que "há mais denúncias de abuso de álcool e de drogas, de assédio moral, de

\footnotetext{
${ }^{10}$ Huffpost Brasil (26/11/14)

${ }^{11}$ Estadão (14/11/14)

12 G1 (12/11/14)

${ }^{13}$ G1 (14/11/14)

${ }^{14}$ Estadão (13/11/14)

${ }^{15}$ Folha de S. Paulo (14/11/14)
} 
intolerância religiosa e étnica". O texto também implicava que existiriam outras causas que teriam motivado sua saída, como o desejo de parcerias com outras universidades, coisa que o regime de exclusividade da USP não deixaria ocorrer.

Essa contraposição é demonstrativa de que a mídia hegemônica não produz necessariamente um discurso homogêneo. Ao contrário, como ponta Ramos (2012), a diversidade e a competição associada à produção de verdade, como um valor que legitima o trabalho jornalístico, produz uma relativa autonomia destes diante das definições oriundas da direção de outros jornais. Este mundo dos jornalistas, nos termos de Bourdieu (1997), é um mundo segmentado em conflitos, concorrências, hostilidades, no qual a produção é coletiva, de conjuntos de redações que são englobadas num conjunto geral de jornalistas. Este mundo é um microcosmo que tem leis próprias e que é definido por sua posição no mundo global e pelas atrações e repulsões que sofre da parte dos outros microcosmos. Dizer que ele é autônomo, que tem sua própria lei, significa dizer que o que nele se passa não pode ser compreendido de maneira direta a partir de fatores externo. Desse modo, gostaria de destacar que as relações de oposição, complementaridade e ressonância tiveram um papel fundamental na construção narrativa em torno dos casos.

O que procuro, nesta apresentação, não é uma totalidade dessas conexões, mas um conjunto provisório gerado pelo adensamento de determinadas relações, conforme elas circulam, de embates e de informações críticas à compreensão e à intervenção social. Desse modo, duas perspectivas, que são cristalizadas e contestadas nos textos jornalísticos, me servem de referência para análise. A primeira perspectiva é a representação do corpo institucional. Nela, afirma-se que mecanismos de apuração dos casos já estariam em execução há um certo tempo. A segunda representa os diversos setores da sociedade mobilizados que, em sua pluralidade de opiniões, contestam a primeira perspectiva. Não são blocos homogêneos, mas servem analiticamente como denominadores comuns mínimos entre perspectivas. Todas as categorias referentes às nomeações de diversos tipos de violências, em especial as violências sexuais e de gênero, foram mantidas como constavam nos textos jornalísticos.

Quanto à primeira perspectiva, os primeiros posicionamentos oficiais foram feitos por José Otávio Costa Auler Junior, diretor da FMUSP, e eram dirigidos estritamente à imprensa. Afirma que "casos de abuso são exceções dentro da faculdade", porém "eventuais violações aos direitos humanos não são toleradas"16, a instituição estava aberta a "receber cada uma das vítimas e apoiá-las". Ao contrário do que havia sido dito, "proteger as vítimas seria a prioridade, pois, "se alguma coisa mancha a imagem da instituição é que casos de violência ocorram no campus". Reiterou que "todos os casos que chegaram ao nosso conhecimento foram objeto de apuração [...]. Mas ficamos impossibilitados de apurar casos que não chegaram a nós por nenhum dos mecanismos existentes" ${ }^{17}$. "As vítimas de estupro

\footnotetext{
${ }^{16} \mathrm{G} 1(12 / 11 / 14)$

${ }^{17}$ Folha de S. Paulo (15/11/14)
} 
devem ter a hombridade e honestidade de comunicar pessoalmente o caso à direção" ${ }^{18}$. A condução da crise ficou a cargo da direção da FMUSP. A reitoria disse respeitar a autonomia da unidade e evitou se manifestar sobre o caso.

Marco Antônio Zago, reitor da USP na época, levou mais de dez dias para se pronunciar. Afirmava que as denúncias deveriam ser tratadas com a devida atenção, tanto pela universidade, por seus aspectos educativos, quanto pelo Ministério Público, no que diz respeito a crimes. Além disso, os episódios de violência seriam reflexo da insegurança que há fora dos muros da USP. Dadas as grandes proporções e dimensões da universidade, era de se esperar que houvesse tais ocorrências, como em qualquer lugar da sociedade ${ }^{19}$. Portanto, a reitoria não estaria sendo absolutamente omissa na apuração dos casos. Ao contrário, a universidade não teria interesse de abafar qualquer caso e estaria fazendo tudo que podia ${ }^{20}$. Postula, ainda, que "se um aluno, professor ou funcionários desrespeitar a lei, terá que arcar com isso e ser processado"21. Pronunciamentos oficiais para a ALESP foram negados com a justificativa de que uma posição oficial da faculdade seria informada após a reunião da Congregação da FMUSP, órgão máximo da unidade, o que fez com que recusassem os convites feitos ${ }^{22}$.

$\mathrm{Na}$ reunião da Congregação, foi apresentado o relatório da comissão nomeada para avaliar a série de denúncias de violação de direitos humanos, na FMUSP, durante cinco meses de apuração ${ }^{23}$. Constatou-se que a violência sexual ocorria de forma repetida na unidade, no entanto, apenas três dos oito casos recebidos pela promotora Paula Figueiredo foram reconhecidos pela instituição ${ }^{24}$. Ademais, o abuso moral seria uma prática constante, e o consumo excessivo de drogas lícitas, ilícitas e de prescrição era rotineiro. A avaliação geral era que "o retrato do que se passa dentro da faculdade não é nada abonador para a instituição". Para Milton Martins, presidente da comissão, "saber que uma aluna foi estuprada em uma festa e ela não se sentiu acolhida pela nossa instituição é uma coisa que chama a nossa responsabilidade, com certeza" ${ }^{25}$. Como resultado da Congregação, aprovouse o Núcleo de Direitos Humanos, órgão independente da instituição ${ }^{26}$ e descrito como uma "medida pioneira que irá garantir acolhimento às vítimas, com assistência jurídica,

\footnotetext{
${ }^{18}$ Huffpost Brasil (26/11/14)

${ }^{19}$ Estadão (24/11/14)

${ }^{20}$ Estadão (09/12/14)

${ }^{21}$ Estadão (24/11/14)

${ }^{22}$ Huffpost Brasil (24/11/14)

${ }^{23}$ G1 (23/11/14)

${ }^{24}$ Huffpost Brasil (26/11/14)

${ }^{25}$ G1 (23/11/14)

${ }^{26}$ Folha de S. Paulo (26/11/14)
} 
psicológica e de saúde" 27 , e proibiu-se o consumo de álcool e festas na universidade até que fosse pensado um modelo consciente de consumo. ${ }^{28}$

Embora Martins fosse contrário, alegou que isso "alivia a barra da universidade e joga o problema para outro lugar, porque, é óbvio, as festas vão continuar.”. Além disso, "ninguém vira estuprador porque bebeu" 29 . Contudo, Zago já era favorável à medida: "essas festas não fazem parte da vida universitária e não deveriam acontecer" ${ }^{30}$.

Quanto à proibição do consumo de álcool e festas na universidade, é essencial tratar das estruturas em torno da organização das festas feitas pelos estudantes. As principais festas da FMUSP reuniam até 3.500 pessoas e tinham cerca de 150 seguranças ${ }^{31}$. Uma outra importante festa era o "Show Medicina", um espetáculo teatral promovido por veteranos e calouros da FMUSP desde 1944, ano de sua criação ${ }^{32}$. Segundo depoimentos de estudantes, o show é cercado de trotes, misoginia, machismo e violação total dos direitos humanos. ${ }^{33}$. Os incidentes de humilhação são vários, envolvendo violência física, sexual e até mesmo sequestros ${ }^{34}$. Vale lembrar que o problema das violências no âmbito universitário vem de longa data ${ }^{35}$.

Tanto a AAA quanto o Centro Acadêmico recebiam "repasses pontuais de verbas da faculdade" e usavam gratuitamente como sede espaços da USP. Entretanto, embora o Show Medicina não recebesse verba da faculdade, já que era realizado por um grupo secreto de estudantes com personalidade jurídica própria, a universidade cedia espaço de suas dependências para sua realização. É a partir desse escopo geral que a promotora Paula de Figueiredo advertiu que esse tipo de conduta não deve ser realizado "em espaço financiado com verbas públicas”. Ao analisar alguns documentos relativos à organização da festa, atestou que eles "comprovam a regularidade das festas, autorizações do Município, mencionaram que informam a polícia, que a organização do evento se dá regularmente”.

\footnotetext{
${ }^{27}$ G1 (14/11/14)

${ }^{28}$ Folha de S. Paulo $(26 / 11 / 14)$

${ }^{29}$ Folha de S. Paulo $(21 / 11 / 14)$

${ }^{30}$ Estadão (26/11/14)

${ }^{31}$ Estadão (27/11/14)

${ }^{32}$ R7 (14/11/14)

${ }^{33}$ R7 (14/11/14)

${ }^{34}$ Huffpost Brasil (15/01/15): Um dos estudantes relatou que "os veteranos podem sequestrar os calouros para aplicar um trote neles a qualquer momento. E assim foi. Pegaram cinco calouros. Tivemos que tirar a roupa e simular prática homossexual na frente de 20 ou 30 pessoas. Foi bastante constrangedor e humilhante. Eu não contei aos meus pais, só ao meu terapeuta".

${ }^{35}$ Estadão (23/02/19): Em 2019, completou-se 20 anos que Edison Tsung Chi Hsueh, calouro da FMUSP, foi encontrado morto na margem de uma piscina da AAA. Em 2013, o Supremo Tribunal Federal arquivou o processo alegando que não havia provas suficientes para punição dos quatro acusados, que era então estudantes, hoje médicos. Tal decisão, manteve o mesmo entendimento do Superior Tribunal de Justiça, os acusados foram absolvidos. Uma das promotoras que atuaram no caso afirmou ter sido ameaçada de morte enquanto investigava o caso.
} 
Contudo, ainda afirmava que "os contratos com as empresas de segurança são feitos de forma vaga, que não tem nenhuma câmera de filmagem em todo o espaço da atlética, que eles não pedem uma lista detalhada com o nome e a documentação de todos os funcionários que atuam nos eventos". Por isso, teria pedido filmagens do interior e dos arredores do auditório da faculdade onde aconteceu o show. Outro pedido foi que a diretoria da FMUSP divulgasse prontamente o valor repassado em verbas da faculdade para as entidades estudantis do curso de medicina. ${ }^{36}$

Começo o desenvolvimento da segunda perspectiva com a oposição de Felipe Scalisa, estudante da FMUSP, à proibição de festas no campus: "Todo mundo sabe que lá fora é pior"37, "se proibir as festas, é provável que façam festas fora e que elas tenham os mesmos problemas"38. Como já havia sido apontado pela professora Heloisa Buarque de Almeida, casos de estupro e violência sexual dentro da universidade são mais comuns em festas e trotes, "[o] que é muito comum é aquela situação da menina que bebe demais, está inconsciente, e os colegas mesmo abusam dela. (...) Normalmente, a menina se sente culpada porque pensa: 'fui eu que bebi demais'. Ela sente vergonha e não conta"39.

Quase todas as vítimas envolvidas nas apurações do MP garantiram que levaram os crimes que sofreram à FMUSP, mas nada foi feito ${ }^{40}$. Inclusive, há um caso, em 2012, quando um aluno abusou sexualmente de uma colega dentro da faculdade. A estudante afirma que denunciou o caso à polícia e à direção da FMUSP, mas que a faculdade pouco fez para apurar de forma aprofundada. A aluna acusa Auler Jr. de não dar apoio a ela e de não abrir processo administrativo disciplinar específico para o caso de estupro. Em apoio, o Coletivo Feminista Geni (FMUSP) faz um manifesto no qual advogam que ${ }^{41}$ :

Quando (o diretor) fala à sociedade que o combate à intolerância e à violência é um trabalho conjunto, mais uma vez (são) palavras jogadas ao vento, porque pelos relatos ouvidos até agora, pela história da vítima que falou em primeira pessoa, o professor Auler não pratica integralmente o que diz. (Coletivo Feminista Geni, matéria publicada em 26 de novembro de 2014).

A promotora Paula Figueiredo, que instaurou o inquérito civil para apurar as denúncias, também afirmou que, no inquérito, já se registrava a ocorrência de oito estupros nos últimos anos. Nessas ocasiões, "as vítimas não obtiveram qualquer suporte da Diretoria, que deixou de dar prosseguimento a procedimentos administrativos de apuração". Em

\footnotetext{
${ }^{36} \mathrm{G} 1(26 / 11 / 14)$

${ }^{37}$ Folha de S. Paulo $(26 / 11 / 14)$

${ }^{38}$ Estadão (26/11/14)

${ }^{39}$ G1 (23/08/14)

${ }^{40}$ Huffpost Brasil (26/11/14)

${ }^{41}$ Huffpost Brasil (26/11/14)
} 
concordância, a deputada estadual Beth Sahão (PT), outra integrante da comissão, criticou que "há casos levantados há mais de 20 anos e impressiona que tais diretores desconheçam tais fatos.", logo em sequência afirma que "há uma certa vontade em não resolver, de uma forma caseira, 'não vamos encontrar os culpados, não vamos responsabilizar ninguém e acabar com isso por aqui'" 42 .

Um dos objetivos da CPI foi apurar o financiamento das festas em que ocorreriam os casos denunciados. Em depoimento, o presidente do Show Medicina contou que o custo da organização da festa era de cerca de 80 mil reais por ano. A verba vinha de contribuições de integrantes e ex-integrantes da organização. O estudante negou que haja violações de direitos humanos durante o evento, mas confirmou a ocorrência de um caso de um aluno que teve de ser hospitalizado após participar da festa. Não foram divulgados detalhes do episódio ${ }^{43}$.

Outra função da CPI foi investigar os dois episódios de estupro até então revelados nas duas primeiras audiências. Além dos casos específicos da USP, a comissão podia apurar denúncias semelhantes em qualquer universidade, pública ou privada, do estado de São Paulo. Diogo, em sua fala, afirma que "a Atlética virou uma fonte de dinheiro. Deixou de ser uma entidade acadêmica para ser foco de negócios, foco empresarial"44. O deputado Marco Aurélio de Souza (PT) lembrou que, com a CPI, pode-se ainda dar mais segurança aos depoentes, pois poderia receber denúncias anônimas ${ }^{45}$. Ademais, Diogo argumentava que "o básico de uma CPI é ter quem fale. Tem que ter o testemunhal, tem que ter a vítima”, pois, "se não tem vítima, pode ser encarado como uma luta política e partidária, embora aqui [Alesp], tudo o que você apresenta tem um viés partidário". A deputada Leci Brandão, por fim, exortou: "peço que não tenhamos interferência política, que é o que acontece quando envolve 'tubarões' e é sempre complicado isso" ${ }^{46}$. A instauração da CPI se deu em meio a muitos conflitos de interesse político, em grande parte, indiretos, entre os diversos atores envolvidos.

\section{Depoimentos}

O primeiro registro de uma denúncia que se tem, realizado pelo Huffpost Brasil, é sobre a FMUSP. Duas alunas denunciaram estupros sofridos em 2004 e 2011, ambos em eventos realizados pela Associação Atlética Acadêmica. Ambas afirmaram sofrer com os traumas e com a impunidade dos envolvidos até aquele momento. A primeira estudante descreveu a rotina que vivia na faculdade, excluída por não gostar das atividades da Atlética. Consequentemente, chegou a entrar em depressão e tomava medicamentos por conta disso.

\footnotetext{
${ }^{42}$ Huffpost Brasil (26/11/14)

${ }^{43}$ Huffpost Brasil (02/12/14)

${ }^{44}$ Estadão (03/12/14)

${ }^{45}$ Huffpost Brasil (03/12/14)

${ }^{46}$ Huffpost Brasil (26/11/14)
} 
Contudo, foi a partir do quarto ano na FMUSP que, segundo ela, começou a "ficar com alguns meninos, só por ficar, tanto que às vezes, nem me lembrava. Isso me envergonhava, mas a coisa foi se tornando natural". O abuso sexual aconteceu em duas ocasiões de 2004, com o mesmo rapaz. Na primeira ocasião, ele tentou forçá-la a fazer sexo oral nele; na segunda, ele sugeriu novamente que ela fizesse com ele e o namorado de uma amiga. A aluna se recusou e o rapaz foi embora. Não obstante, no dia seguinte, ela acordou nua e com uma camisinha presa no ânus. "Não fiz boletim de ocorrência, porque achava que só ia me expor. Senti muita humilhação". Teria guardado segredo até 2013, quando conseguiu relatar o que viveu ao marido, pois acordava com crises súbitas de choro.

Resolveu denunciar o fato à CPI, porque soube que o ocorrido não era apenas um fato isolado. Isso também foi expresso por segunda vítima, que viveu duas situações de estupro: "fico impressionada ao ouvir os relatos, as histórias se repetem". A primeira foi perpetuada por um diretor da AAA, que já era conhecido por assediar diversas calouras. Ele tentou abaixar as calças dela. Com isso, ela acabou sendo caluniada por ele dentro da própria instituição. De acordo com ela, essas situações "misóginas, machistas e perversas são recorrentes", com veteranos chamando calouras de putas e agindo como se fossem "donos" delas. A segunda situação ocorreu numa festa organizada pela AAA, em 2011, no Bosque da Cidade Universitária. Após tomar duas tequilas, acordou no hospital, junto com os diretores da AAA. Como havia a suspeita de estupro, ela foi medicada com retrovirais. Pouco tempo depois, o abuso foi confirmado pelos próprios diretores e teria sido praticado por um funcionário da USP. Contudo, os mesmos se negaram a ajudá-la a denunciar. Além disso, ela acabou conhecida nos corredores como "a estudante que transou com um segurança". Assim como outras estudantes da FMUSP, ela criticou a omissão da instituição. Apesar de tudo, ela afirma "não ter medo algum" de represálias, graças ao apoio que recebeu. "Tenho uma rede de apoio institucional. Sozinha não teria conseguido".

Uma pesquisa sobre a violência no ambiente universitário foi feita com alunos da Faculdade de Medicina da USP, em 2013, um ano antes da publicização dos casos. Cerca de $30 \%$ dos alunos participaram da pesquisa. $92 \%$ dos estudantes informaram ter sofrido pelo menos um episódio de violência física ou verbal na faculdade, de humilhação a violência sexual. Desses, $30 \%$ consideraram que o fato foi grave ${ }^{47}$.

Em outro caso, uma aluna do $5^{\circ}$ ano da FMUSP relatou ter sofrido tentativa de estupro, no início de 2013, durante uma festa no porão da universidade. "Dois alunos me abordaram e falaram pra eu ir para o carro deles, eles me beijaram a força, enfiaram a mão na minha calça e insistiam pra eu entrar no carro. Eles se aproveitaram que eu estava um pouco alcoolizada.". Mas, "eu comecei a entrar em desespero, mas não sabia muito bem o que fazer. Ao fim, uma aluna passou e conseguiu me tirar de lá". Após o ocorrido, ela procurou a Comissão de Graduação da Faculdade que, na ocasião, a orientou a fazer um boletim de ocorrência. Apesar disso, depois de certo tempo, ninguém a procurou para dar

${ }^{47}$ Folha de S. Paulo $(21 / 01 / 15)$ 
continuidade ao processo. Ela tanto ficou sem saber o que podia fazer administrativamente, como não recebeu apoio psicológico da instituição.

No final de 2013, foi aberta uma sindicância interna, mas o agressor não foi ouvido e, segundo a reportagem da Folha ${ }^{48}$, ela não teve acesso ao seu próprio depoimento. Ademais, relatou que havia um questionário que relacionava o álcool a um possível desvio moral seu. Por todos esses motivos, ela preferiu não assinar o seu relato, pois, a sindicância foi "conduzida" pela instituição. Contudo, a reportagem do Estadão ${ }^{49}$ apresentava uma outra versão dos acontecimentos. Nela, a aluna acusa a comissão de ter forjado seu relato sobre o caso. Além disso, teria tido acesso aos documentos da sindicância e poderia comprovar que o depoimento que constava como seu não era de sua autoria. Apesar dessa divergência de relatos, em ambas as matérias é apontado que a sindicância foi fechada sob a alegação de o caso ter sido consensual. Enquanto na Folha apontava-se que quando casos similares foram divulgados pela imprensa na metade de 2013 e uma nova sindicância foi aberta, no Estadão foi traçada uma relação entre a publicização das denúncias e as audiências públicas que deram origem à CPI. Outra divergência entre as duas reportagens se referia ao procedimento da segunda sindicância: na Folha, a aluna afirmava que já ter deposto novamente e estaria esperando o novo resultado; no Estadão, ela afirmava que o procedimento da sindicância teria sido diferente da primeira, ressaltando que a primeira comissão foi composta de três homens e uma mulher e a segunda, de três mulheres e um homem.

Em seu depoimento à CPI, José Otávio Costa Auler Junior, diretor da FMUSP, afirmou que a segunda sindicância havia sido finalizada. No parecer da comissão, que apurou o caso, ficou concluído que houve abuso sexual e os dois alunos envolvidos deveriam ser punidos. Os alunos acusados poderiam ser expulsos - um é estudante do sexto ano e outro já terminara o curso e estava em residência médica ${ }^{50}$. Além disso, quaisquer alunos envolvidos em casos de violência sexual seriam punidos pela universidade. Na reportagem da Folha ${ }^{51}$, as punições, segundo o diretor, foram recomendadas por sindicância, mas ainda seriam referendadas por colegiado especial, em conjunto com a procuradoria da USP. Porém, ele assegurou ser "improvável que as punições não sejam aprovadas".

Novamente, um ângulo diferenciado é apresentado pelo Estadão ${ }^{52}$ : nele, a acusação da aluna é respondida pelo diretor. Auler afirmou que confiava nos professores que faziam parte da comissão, mas que iria apurar tal denúncia e encaminhar à procuradoria da USP. Também justificou que a primeira sindicância era apenas uma "apuração preliminar que não se satisfez". Foi apresentado que o deputado Diogo questionou o resultado das apurações internas e afirmou que se a sindicância já "nasce morta", sendo que, sem apoio da universidade, não haveria investigações. Auler, então, ressaltava que ficou "envergonhado"

\footnotetext{
${ }^{48}$ Folha de S. Paulo (15/01/15)

${ }^{49}$ Estadão (15/01/15)

${ }^{50}$ Estadão (15/01/15)

${ }^{51}$ Folha de S. Paulo (15/01/15)

${ }^{52}$ Estadão (15/01/15)
} 
com os acontecimentos, mas que nunca teria omitido nenhum dos casos que foram levados formalmente à FMUSP. Ainda disse "deixo compromisso público com vocês de aprimorar os mecanismos da instituição e de modificar esta cultura". Nesse mesmo sentido, na Folha, ele afirma que "tudo passa por uma mudança institucional, de uma cultura de mais de 100 anos. É difícil, mas faremos. Eu vou me empenhar profundamente num projeto de mudança".

Por fim, advogava que "a instituição precisa de mudanças culturais que estão alinhadas a uma maior respeitabilidade de direitos humanos [...]. Nós reconhecemos e somos solidários às vítimas e nossa prioridade é melhorar os canais de denúncia e aprimorar os mecanismos de acolhimento e apoio psicológico [...]. Gradativamente também iremos mudar o currículo da universidade para que haja mais disciplinas relacionadas a direitos humanos.". A Folha também afirma que Auler reconheceu a gravidade dos casos, e mais, que ele possuía uma agenda mensal com todos os alunos, em que atendia várias demandas dos coletivos em favor dos direitos humanos da universidade. No Estadão, é dito que Auler aproveitou a ocasião para exibir o "pacote" de medidas de prevenção ao estupro e à violência descritas acima. O grande diferencial dessa reportagem foi que nela uma outra novidade era anunciada pelo diretor: a recepção dos calouros, em 2015, seria "diferente", com a presença dos pais e com orientações sobre onde relatar eventuais abusos e violências. Também não deixava de afirmar que "a Faculdade de Medicina é uma instituição que busca resolver todos os problemas e servir de modelo a outras instituições". Na reportagem da Folha ${ }^{53}$, não há referência alguma sobre isso.

Em diversos momentos durante a CPI, os dois primeiros anos na FMUSP foram descritos como os piores para os calouros, em grande parte pelo "Show Medicina". Durante seu depoimento na CPI, José Otávio Costa Auler Junior, diretor da FMUSP, afirmou que quaisquer alunos envolvidos em casos de violência sexual seriam punidos pela universidade. E ainda afirmou que "quem não gosta de gente não pode ser médico" ${ }^{54}$.

Durante uma das sessões da CPI, foram proferidas algumas análises sobre a problemática dos trotes. Marco Akerman, professor da Faculdade de Saúde Pública, defendeu uma análise mais profunda em relação ao tema. "A gente tem que trabalhar com os determinantes sociais do trote. Nós falamos em prevenir, mas é preciso entender a lógica. $\mathrm{O}$ trote é uma maneira de introduzir a hierarquia". Segundo ele, na Faculdade de Medicina, o trote tem uma lógica de poder que vai se estender para toda a sociedade.

\section{Desenvolvimentos posteriores à CPI}

A CPI durou 83 dias, foram feitas 37 audiências. Nos últimos dez anos, há indícios de, pelo menos, 110 estupros ${ }^{55}$ cometidos no chamado "quadrilátero da saúde", segundo o relatório final da investigação feito em colaboração com a professora Maria Ivete Boulos,

\footnotetext{
${ }^{53}$ Folha de S. Paulo (15/01/15)

${ }^{54}$ Folha de S. Paulo (15/01/15)

${ }^{55}$ Huffpost Brasil (13/03/15)
} 
responsável pelo Núcleo de Direitos Humanos na FMUSP desde de sua criação em $2014^{56}$. Podemos destacar dois resultados principais: a aprovação de uma lei que impediu o trote, com a previsão de expulsão de alunos e exoneração de funcionários envolvidos; e a suspensão do Show Medicina, a pedido do Ministério Público Estadual (MPE) ${ }^{57}$.

Contudo, dois anos após a proibição das festas, a AAA voltou a anunciar a volta da festa tradicional com uma outra roupagem. Embora mantendo essencialmente a estrutura anterior, a grande diferença é que ela deixou de ocorrer nas dependências da universidade com uma aludida promessa de serem mais atentos quanto as situações de possível vulnerabilidade. A Frente Feminista Universitária de São Paulo, organização que reúne coletivos feministas da USP e de outras instituições de ensino, propôs o boicote ao evento por acreditar que a festa carrega consigo "uma bagagem histórica irreversível" ${ }^{2}$. Em 2017, verificou-se também que o Show Medicina ainda era divulgado na unidade ${ }^{59}$.

As investigações resultaram em dez denúncias formais de estupro, das quais seis dizem respeito à FMUSP. Dos dez casos, três resultaram em sindicância ${ }^{60}$. Desses alunos, apenas um foi suspenso, por seis meses. A pedido dos diversos coletivos, a suspensão foi prolongada por mais um ano. Em setembro de 2016, a prorrogação da suspensão chegou ao fim, antes mesmo do processo judicial ter sido encerrado, o que permitiria que o aluno pudesse concluir o curso de Medicina. Todavia, o anúncio da possibilidade de sua colação de grau reacendeu o debate acerca da impunidade dos agressores na Universidade e a preocupação com a segurança das alunas ${ }^{61}$. Alunos e alunas da unidade, juntamente com outros coletivos foram à FMUSP entregar ao diretor um documento em repúdio à falta de punição nos casos de violência sexual na instituição, assinado por cerca de 1 mil pessoas, dentre elas, advogados, sociólogos e estudantes. Os alunos também colocaram, nos portões da instituição, panos pintados com os dizeres "médico estuprador não cola" e "USP, $1^{\text {a }}$ no ranking de conivência com estupro"62. Em nota pública, a Rede Não Cala pronunciou-se dizendo que "a apuração realizada pela Faculdade de Medicina optou por aplicar uma suspensão e aguardar o resultado do processo jurídico". Entretanto, "tendo em vista a experiência de algumas de nós na realização de pesquisas na área, bem como nossa própria condição feminina, sabemos que as palavras das mulheres têm valor e precisam ser muito mais consideradas”. Portanto, "a omissão da Universidade tem sido justificada pelo receio de se cometer injustiça com os possíveis agressores. Questionamos por que a universidade não teme cometer injustiça com as possíveis vítimas" ${ }^{33}$.

\footnotetext{
${ }^{56}$ Jornal do Campus (19/11/16)

${ }^{57}$ Estadão (02/01/16)

58 Jornal do Campus (15/05/16)

${ }^{59}$ Jornal do Campus $(24 / 10 / 17)$

${ }^{60}$ Estadão (02/01/16)

61 Jornal do Campus (19/11/16)

${ }^{62}$ Estadão (07/04/15)

${ }^{63}$ Rede Não Cala (25/10/16)
} 
Não obstante, a FMUSP fez secretamente a colação de grau, e com isso, o acusado poderia receber o registro no CRM e exercer a profissão de médico, mesmo ainda sendo réu na Justiça Comum e esperando ser julgado ${ }^{64}$. A professora Maria Ivete Boulos tentou impedir que o acusado viesse a receber seu diploma, o que a fez receber uma ordem de afastamento de seu cargo por e-mail ${ }^{65}$. Tal decisão foi amplamente contestada, já que ela possui experiência no atendimento a vítimas de violência sexual, enquanto o substituto é especialista em cirurgia. O caso também é presente na nota da Rede Não Cala ${ }^{66}$ citada acima, nela declaram que o núcleo presidido pela professora vinha realizando atividades essenciais para enfrentamento da violência sexual e de gênero "numa instituição que não raras vezes age como se as mulheres valessem menos, as vítimas fossem culpadas por situações de assédio e estupro e não merecessem respeito e nem justiça." ${ }^{67}$. Em resposta a ambos acontecimentos, um novo ato foi realizado na unidade reunindo reuniu alunas e coletivos feministas.

Logo após o ato, o Conselho Regional de Medicina do Estado de São Paulo (Cremesp) se reuniu e deliberou o indeferimento do registro profissional (CRM) do aluno até que fosse concluída a avaliação jurídica do caso. Em fevereiro de 2017, o acusado foi absolvido, segundo o juiz que presidiu havia "inconsistência das declarações da ofendida" 68 , o fato de a estudante ter entrado no quarto do acusado "de livre e espontânea vontade" e ter dito a duas amigas, que estavam do lado de fora, "que ali permaneceria", estariam entre os motivos para julgar improcedente a ação ${ }^{69}$. A defesa recorreu da decisão. Em 2018, o acusado foi absolvido em segunda instância com argumentos congruentes com os anteriores. Segundo a advogada Marina Ganzarolli, mesmo após o acusado "ter afirmado que dopou as vítimas, o juiz usou o fato de que ela consentiu entrar no apartamento para provar consentimento no ato sexual”, para ela, isso seria um grande indício de que o judiciário não parece compreender o que é consentimento ${ }^{70}$. Hoje, o acusado atua como médico com um registro do Conselho Regional de Medicina emitido em Pernambuco, já que o CREMESP manteve o indeferimento. Ele alega que pretende se especializar em Ginecologia e Obstetrícia $^{71}$.

\section{Considerações Finais}

\footnotetext{
${ }^{64}$ Revista Cult (04/11/16)

${ }^{65}$ Carta Capital (16/08/18)

${ }^{66}$ Rede Não Cala constituída em abril de 2015, por professoras e pesquisadoras de diferentes institutos da USP em oposição à violência institucional, tendo como principal foco dar às vítimas um suporte que elas não encontraram na Universidade

${ }^{67}$ Rede Não Cala $(25 / 10 / 16)$

${ }^{68}$ Nexo Jornal (19/07/18)

${ }^{69}$ Jornal do Campus $(19 / 11 / 16)$

70 Carta Capital (03/08/18)

71 Carta Capital (16/08/18)
} 
Ao longo deste artigo procurei apresentar algumas das formas incipientes que a teoria antropológica nos oferece para tratar do digital. Embora a temática ainda seja pouco presente na formação inicial em Ciências Sociais, isso não impede totalmente que o aluno não possa desenvolver uma etnografia no contexto digital utilizando-se, em parte, do arcabouço teórico que já possui. Longe de uma completa reorientação teórica e metodológica, busquei apresentar um dos caminhos que encontrei para desenvolver a pesquisa.

À primeira vista pode-se achar estranha a combinação de tantos referenciais distintos, contudo o que é importante frisar é que nossas noções de fronteiras rígidas entre as fronteiras do digital e o analógico, entre o on-line e off-line estão cada vez mais desestabilizadas, tal distinção pode até se encontrar superada pelos nossos interlocutores, pelas relações que tecem ou até mesmo pelos usos que fazemos dessas tecnologias no nosso cotidiano. Entendendo que tal pesquisa de campo não tem limites claros do que vem a se constituir como campo, que decorre de momentos arbitrários com que nos deparamos ao longo da pesquisa. Desse modo, o empreendimento etnográfico nos aponta que é preciso estar atento aos usos coletivos e aos desenvolvimentos recentes dessas tecnologias, entendendo que esses valores estão sempre em disputa e atravessados por distintos discursos e relações de poder.

Tudo isso coloca em contínua torção empiria e teoria, nos mostrando, como advoga Peirano (2014), na qual há uma necessidade permanente de conceber novas estratégias e formas de pesquisa, levando a um refinamento da disciplina. Não há um modo básico de realizar isso e não procurei apresentar aqui um roteiro metodológico a ser empregado etapa por etapa. Isso vai depender dos desenvolvimentos e demandas de cada pesquisa etnográfica. A experimentação etnográfica é um devir.

\section{Referências Bibliográficas}

BAYM, Nancy. (2010). Personal connections in the digital age. Cambridge: Polity.

BOURDIEU, Pierre. (1989). O poder simbólico. Lisboa, Difel.

BOURDIEU, Pierre. (1997). Sobre a televisão. Rio de Janeiro, Jorge Zahar.

CHAMPAGNE, Patrick. (1998). “A visão midiática” In: BOURDIEU, Pierre (org.). A miséria do mundo. $2^{\text {a }}$ ed. Petrópolis: Vozes.

COLEMAN, Gabriella. (2010). “Ethnographic Approaches to Digital Media”. Annual Review of Anthropology, vol.39, n.1, p.487-505.

COULDRY, Nick. (2003). "Beyond the hall of mirrors? Some theoretical reflections on the global contestation of media power” In: COULDRY, Nick; CURRAN, James. Contesting Media Power: alternative media in a networked world. Lanham: Rowman \& Littlefield. COULDRY, Nick; CURRAN, James. (2003). “The Paradox of Media Power” In: COULDRY, Nick; CURRAN, James. Contesting Media Power: Alternative Media in a Networked World. Lanham: Rowman \& Littlefield. 
CUNHA, Olívia Maria Gomes da. (2004). "Tempo imperfeito: uma etnografia do arquivo”. Mana, Rio de Janeiro, v. 10, n. 2, p. 287-322.

CURRAN, James; FENTON, Natalie; FREEDMAN, Des. (2012). Misunderstanding the internet. London: Routledge.

FABIAN, Johannes. (2008). Ethnography as Commentary. Writing from the Virtual Archive. Durham: Duke University Press.

GEERTZ, Clifford. (2015). A Interpretação das Culturas. Rio de Janeiro: LTC Editora.

HALL, Stuart. (2006). Da Diáspora: identidades e mediações culturais. Belo Horizonte, Editora da UFMG.

HINE, Christine. (2000). Virtual ethnography. California: Sage Publications Ltd.

HORST, Heather; MILLER, Daniel. (2012). "The digital and the human a prospectus for digital anthropology" In: HORST, Heather; MILLER, Daniel. (ed.). Digital anthropology. Berg: London

LANDINI, Tatiana Savoia. (2006). "Violência sexual contra crianças na mídia impressa: gênero e geração". Cadernos Pagu, vol.26.

LOWENKRON, Laura; FERREIRA, Letícia. (2014). "Anthropological perspectives on documents: Ethnographic dialogues on the trail of police papers". in: Vibrant, v. 11, n. 2.

MAGNANI, José Guilherme. (2009). “Etnografia como prática e experiência” In: Horizontes Antropológicos, v.15, n.32, p.129-156.

MARCUS, George. (1995). "Ethnography in/of the World System: The Emergence of Multi-sited Ethnography”. Annual Review of Anthropology, vol.24.

OLIVEIRA, Roberto Cardoso. (1998). "O trabalho do antropólogo: olhar, ouvir, escrever" In: O Trabalho do Antropólogo. São Paulo: Paralelo/Ed.Unesp, p. 17-35.

PARREIRAS, Carolina. (2015). Altporn, corpos, categorias, espaços e redes: um estudo etnográfico sobre pornografia online. Tese de Doutorado. Campinas: UNICAMP.

PEIRANO, Mariza. (2014). “Etnografia não é método” In: Horizontes Antropológicos, Porto Alegre, ano 20, n. 42, p; 377-391.

RAMOS, Jair de Souza. (2012). “Toma que o aborto é teu: a politização do aborto em jornais e na web durante a campanha presidencial de 2010”. Revista Brasileira de Ciência Política, n.7, p. 55-82.

STRATHERN, Marilyn. (2006). O Gênero da Dádiva: problemas com mulheres e problemas com a sociedade na Melanésia. Campinas: Ed.Unicamp.

\section{sobre o autor}

\section{Felipe Paes Piva}

Graduando em Ciências Sociais da Universidade de São Paulo.

Recebido em: 30/09/2020

Aceito para publicação em: 12/12/2020 